\title{
Philadelphia Chromosome-positive Acute Lymphoblastic Leukemia Incidentally Detected by Fluorodeoxyglucose- positron Emission Tomography/Computed Tomography at a Health Checkup
}

\author{
Hisako Kunieda ${ }^{1}$, Ryunosuke Denda ${ }^{1}$, Kohei Yamazaki ${ }^{1}$, Maki Hirao ${ }^{1}$, Yuiko Tsukada ${ }^{1}$, \\ Yu Iwabuchi ${ }^{2}$, Eisuke Shiomi ${ }^{3}$, Shigeru Watanabe ${ }^{4}$, \\ Shinichiro Okamoto ${ }^{1,5}$ and Takahide Kikuchi ${ }^{1}$
}

\begin{abstract}
:
We herein report a case of Philadelphia chromosome-positive acute lymphoblastic leukemia (Ph-ALL) that was incidentally detected by fluorodeoxyglucose-positron emission tomography $\left({ }^{18} \mathrm{~F}\right.$-FDG PET)/computed tomography (CT) at a health checkup. At that time, the findings of a physical examination and blood tests were all normal, except for the diffuse bone marrow uptake (maximum standardized uptake value: 6.3). One month later, when the blood counts remained in the normal ranges, a bone marrow examination confirmed the diagnosis of Ph-ALL. Although a diffuse bone marrow uptake of ${ }^{18} \mathrm{~F}-\mathrm{FDG}$ is observed in some benign conditions, physicians should also consider the possibility of hematological malignancies, including acute leukemia, even when that is the only abnormal finding.
\end{abstract}

Key words: acute lymphoblastic leukemia, bone marrow, ${ }^{18}$ F-FDG uptake, PET/CT, health checkup

(Intern Med Advance Publication)

(DOI: 10.2169/internalmedicine.8900-21)

\section{Introduction}

Fluorodeoxyglucose-positron emission tomography $\left({ }^{18} \mathrm{~F}-\right.$ FDG PET)/computed tomography (CT) has been widely used to detect a variety of hematopoietic malignancies, such as lymphoma. PET/CT is also being increasingly incorporated as part of health checkups in Japan. For the diagnosis of acute leukemia, PET/CT has little value, as the majority of acute leukemia cases are suspected based on abnormal findings of a peripheral blood examination. However, there have been a few reported cases of acute leukemia that was initially detected by PET/CT based on a diffuse bone marrow uptake, and the diagnosis was confirmed by bone marrow aspiration or a biopsy (1-3).
We herein report a case of acute lymphoblastic leukemia that was incidentally detected by ${ }^{18} \mathrm{~F}-\mathrm{FDG} \mathrm{PET} / \mathrm{CT}$ at the time of a health checkup.

\section{Case Report}

A 56-year-old Japanese man with no significant medical history was referred to our hospital for the evaluation of a diffuse ${ }^{18} \mathrm{~F}$-FDG [maximum standardized uptake $\left(\mathrm{SUV}_{\max }\right)$ : 6.3] uptake of the bone marrow. The uptake was observed in the vertebrae, ilium, and ribs but not in the bone marrow of the appendicular skeleton. The inhomogeneous uptake of ${ }^{18}$ F-FDG was also observed in some parts of the axial skeleton (Fig. 1). He had undergone a health checkup annually for the last two years and had never been shown to have any

${ }^{1}$ Department of Hematology, Saiseikai Central Hospital, Japan, ${ }^{2}$ Department of Radiology, Keio University School of Medicine Graduate School of Medicine, Japan, ${ }^{3}$ Department of Radiology, Saisekai Central Hospital, Japan, ${ }^{4}$ Department of Health and Productivity Management, Nippon Life Insurance Company, Japan and ${ }^{5}$ Department of Hematology, Keio University School of Medicine Graduate School of Medicine, Japan Received: October 24, 2021; Accepted: December 17, 2021; Advance Publication by J-STAGE: February 26, 2022 Correspondence to Dr. Hisako Kunieda, hisacoueda37@gmail.com 
(a)

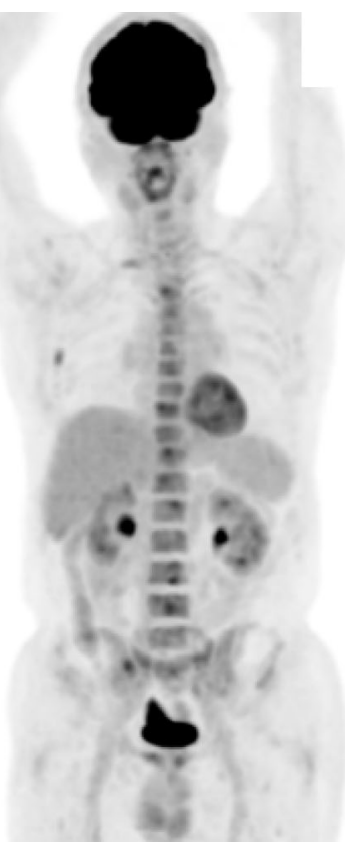

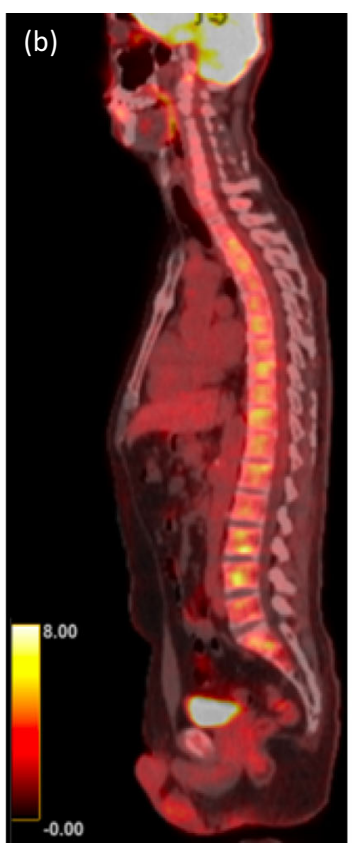

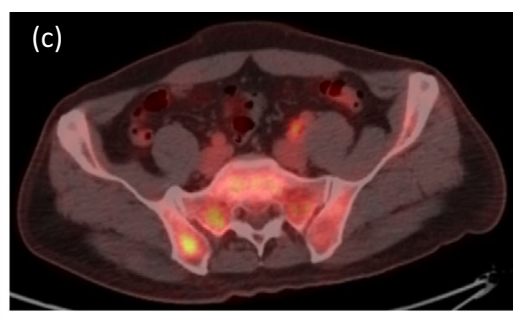

Figure 1. The findings of PET/CT at the time of health checkup. Maximum intensity projection PET image (a) and PET/CT images (b, c). PET/CT showed the diffuse but focally inhomogeneous uptake of ${ }^{18}$ F-FDG. The $S U V_{\max }$ of right ilium was 6.3 .

abnormal findings except for hyperuricemia.

At the time of this health checkup, he was doing well without any symptoms, including a fever, bone pain, and weight loss. He also denied any recent febrile or bleeding episodes. A complete blood count (CBC) showed a white

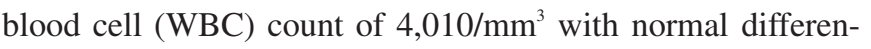
tials, a hemoglobin $(\mathrm{Hb})$ level of $13.8 \mathrm{~g} / \mathrm{dL}$, and a platelet count of $204 \times 10^{3} / \mathrm{mm}^{3}$. All of the counts remained within the normal ranges; however, a slight decrease was observed in all counts compared with the counts at the time of the health checkup the previous year (Table). The results of routine blood chemistry evaluations, including the values of lactate dehydrogenase $(\mathrm{LDH})$ and $\mathrm{CRP}$, also remained within normal ranges.

One month after the health checkup, he visited our service for a further evaluation. The physical examination at that time did not detect any abnormal findings, including hepatosplenomegaly. The hematological examination revealed a WBC count of $4,800 / \mathrm{mm}^{3}$ with $3 \%$ of atypical lymphocytes and no blasts, a $\mathrm{Hb}$ level of $14.1 \mathrm{~g} / \mathrm{dL}$, and a platelet count of $153 \times 10^{3} / \mathrm{mm}^{3}$ (Table). The results of routine blood chemistry tests were only remarkable for mild elevation of $\mathrm{LDH}$ (266 IU/L, normal range: 120-220) and ferritin (332 ng/mL, normal range: 14-303). However, bone marrow aspiration revealed hypercellular marrow with $87 \%$ blasts (Fig. 2). The leukemic blasts were negative for myeloperoxidase staining, and flow-cytometric analyses confirmed that the cells were positive for CD10, CD19, CD20, CD34, and cytoplasmic CD79a. Reverse transcription polymerase chain reaction (RT-PCR) detected the presence of a minor $B C R / A B L 1$ transcript (coding for a 190-kDa protein). A cytogenetic analysis also showed $\mathrm{t}(9 ; 22)(\mathrm{q} 34 ; \mathrm{q} 11.2)$ in 20 out of 20 meta- phases. Based on those findings, he was diagnosed with Philadelphia chromosome positive-acute lymphoblastic leukemia (Ph-ALL).

He was placed on initial induction therapy consisting of dasatinib (140 mg/day) and prednisolone $\left(60 \mathrm{mg} / \mathrm{m}^{2}\right)$. Complete remission (CR) was obtained one month later, and he subsequently underwent allogeneic hematopoietic cell transplantation from his HLA-haploidentical daughter after conditioning with fludarabine $\left(150 \mathrm{mg} / \mathrm{m}^{2}\right)$, cyclophosphamide $(29 \mathrm{mg} / \mathrm{kg})$ and total body irradiation (2 Gy). There were no major transplant-associated complications. He remained in complete molecular remission for 200 days after transplantation while taking dasatinib (50 mg every other day) [please check this carefully].

\section{Discussion}

${ }^{18}$ F-FDG PET/CT has been widely used for the detection/ staging and assessment of response to therapies for a variety of lymphomas and other hematological malignancies. However, PET/CT has only been seldomly used for this purpose in acute leukemia, and bone marrow aspiration or a biopsy remains the gold standard for detecting the disease and assessing the response to treatment. In some cases, however, the detection of focal bone-localized relapse by ${ }^{18} \mathrm{~F}-\mathrm{FDG}$ PET/CT has been reported in acute leukemia even though a bone marrow examination failed to demonstrate leukemic cell growth $(4,5)$.

There are also some cases in which ALL was detected incidentally by a diffuse increased uptake of ${ }^{18} \mathrm{~F}-\mathrm{FDG}$ on PET/ CT. Those cases presented with a fever of unknown origin (FUO) and/or generalized bone pain with normal blood 
Table. Serial Results of CBC and Blood Chemistry (at Health Check-up, at the First Visit to Our Hospital, and at the Time of Health Check-up Last Year).

\begin{tabular}{|c|c|c|c|c|}
\hline Timing of test & $\begin{array}{c}\text { At health check-up } \\
\text { a year before }\end{array}$ & $\begin{array}{c}\text { A health check-up } \\
\text { this time }\end{array}$ & $\begin{array}{l}\text { At the time of } \\
\text { visiting our hospital }\end{array}$ & \\
\hline \multicolumn{5}{|l|}{$\mathrm{CBC}$} \\
\hline WBC & 5.96 & 4.01 & 4.8 & $\times 10^{3} / \mathrm{uL}$ \\
\hline neut & 58.4 & 57.4 & 58 & $\%$ \\
\hline lymp & 32.6 & 35.7 & 35 & $\%$ \\
\hline mono & 7.2 & 4.7 & 1 & $\%$ \\
\hline eosi & 1.3 & 2.0 & 1 & $\%$ \\
\hline baso & 0.2 & 0.2 & 0 & $\%$ \\
\hline MT & - & - & 1 & $\%$ \\
\hline MY & - & - & 1 & $\%$ \\
\hline A-lymp & - & - & 3 & $\%$ \\
\hline $\mathrm{RBC}$ & 532 & 460 & 484 & $\times 10^{4} / \mathrm{uL}$ \\
\hline $\mathrm{Hb}$ & 15.7 & 13.8 & 14.1 & $\mathrm{~g} / \mathrm{dL}$ \\
\hline $\mathrm{Ht}$ & 47.0 & 40.8 & 43.0 & $\%$ \\
\hline Plt & 253 & 204 & 153 & $\times 10^{3} / \mathrm{uL}$ \\
\hline Reti & 1.5 & 2.0 & 1.7 & $\%$ \\
\hline \multicolumn{5}{|l|}{ Blood chemistory } \\
\hline $\mathrm{TP}$ & 7.5 & 6.8 & 7.1 & $\mathrm{~g} / \mathrm{dL}$ \\
\hline Alb & 5.1 & 4.8 & 5.1 & $\mathrm{~g} / \mathrm{dL}$ \\
\hline $\mathrm{Na}$ & 142 & 144 & 143 & $\mathrm{mEq} / \mathrm{L}$ \\
\hline $\mathrm{K}$ & 4.3 & 4.2 & 4.6 & $\mathrm{mEq} / \mathrm{L}$ \\
\hline $\mathrm{Cl}$ & 103 & 107 & 104 & $\mathrm{mEq} / \mathrm{L}$ \\
\hline $\mathrm{Ca}$ & 9.5 & 9.4 & 10.3 & $\mathrm{mg} / \mathrm{dL}$ \\
\hline BUN & 19.1 & 9.7 & 15 & $\mathrm{mg} / \mathrm{dL}$ \\
\hline Cre & 1.00 & 0.86 & 0.94 & $\mathrm{mg} / \mathrm{dL}$ \\
\hline UA & 9.0 & 6.0 & 8.0 & $\mathrm{mg} / \mathrm{dL}$ \\
\hline T-Bil & 3.8 & 1.2 & 1.4 & $\mathrm{mg} / \mathrm{dL}$ \\
\hline AST & 28 & 18 & 28 & $\mathrm{U} / \mathrm{L}$ \\
\hline ALT & 30 & 17 & 29 & $\mathrm{U} / \mathrm{L}$ \\
\hline $\mathrm{LDH}$ & 173 & 167 & 266 & $\mathrm{U} / \mathrm{L}$ \\
\hline ALP & 182 & 46 & 128 & $\mathrm{U} / \mathrm{L}$ \\
\hline$\Gamma$-GTP & 28 & 20 & 23 & $\mathrm{U} / \mathrm{L}$ \\
\hline CRP & $<0.10$ & $<0.10$ & $<0.3$ & $\mathrm{mg} / \mathrm{dL}$ \\
\hline
\end{tabular}

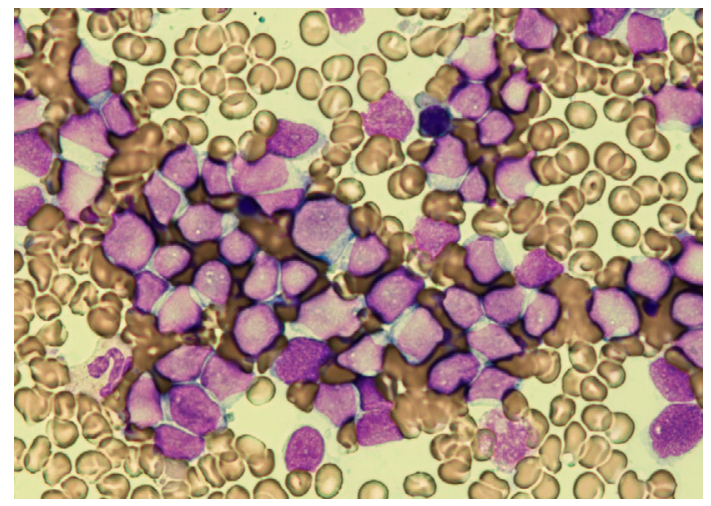

Figure 2. The findings of bone marrow aspiration. Bone marrow aspiration revealed a hypercellular marrow with $87 \%$ blasts (May-Giemsa stain, $\times 400$ ). The blasts were large and heterogeneous in size with a high $\mathrm{N} / \mathrm{C}$ ratio. Their nuclei were irregular and contained one or more prominent nucleoli and vacuoles. counts, and a bone marrow examination confirmed the diagnosis while the findings of peripheral blood examinations or CBC did not reveal any abnormalities except for mild anemia that was considered to have been caused by inflammation (1-3, 6). However, there have been no reported cases of acute leukemia at the time of a health checkup with suggestive ${ }^{18}$ F-FDG PET/CT images as the sole abnormal finding.

Although the main source of a diffuse ${ }^{18} \mathrm{~F}$-FDG uptake in the bone marrow is the infiltration of malignant cells, it is sometimes observed during the hematopoietic recovery phase after chemotherapy, infection, and the administration of growth factors, such as colony-stimulating growth factor or erythropoietin. If the uptake of ${ }^{18} \mathrm{~F}$-FDG is markedly elevated in the bone marrow, malignant infiltration (MI) is very likely; however, if the uptake at the bone marrow is equivalent or slightly higher than that of the liver, it is difficult to determine whether it is due to malignant infiltration or a benign process. The ${ }^{18} \mathrm{~F}$-FDG uptake in benign diseases and under physiological conditions is low. Inoue et al. reported that in most cases, the diffuse uptake at the bone marrow 
was slight and moderate, often presenting as an uptake level corresponding to or slightly higher than that in the liver. In these situations, it is sometimes difficult to determine whether this is due to MI, including acute leukemia, or a benign condition (7). Zhou et al. also found that a considerable proportion of MI patients had a similar $\mathrm{SUV}_{\max }$ at the bone marrow to non-MI patients. This is manly seen in patients with chronic myelogenous leukemia, multiple myeloma, and lymphoplasmacytic lymphoma. Thus, they developed a decision tree combining the $\mathrm{SUV}_{\max }$ at the bone marrow with the $\mathrm{SUV}_{\max } \mathrm{AP} / \mathrm{AX}$ (ratio of $\mathrm{SUV}_{\max }$ at the bone marrow of the appendicular skeleton to that at the axial skeleton), the presence of a fever, and hepatomegaly and achieved a sensitivity of $81.0 \%$, a specificity of $98.4 \%$, and an accuracy of $94 \%$ for the prediction of MI (8). The present case met their criteria for the $\mathrm{SUV}_{\max }$ at the bone marrow (6.3), suggesting the usefulness of their approach.

In this case, the uptake of ${ }^{18} \mathrm{~F}-\mathrm{FDG}$ was inhomogeneous in some vertebrae and pelvic bones; however, these parts were not associated with osteosclerotic and osteolytic lesions. These findings are not consistent with those of a hyperactive bone marrow condition caused by anemia or infection, in which the bone marrow findings are typically homogeneous. Thus, this finding is similar to that of the infiltration of lymphoma into the bone marrow.

In the present case, despite the massive infiltration of leukemic cells into the bone marrow, the peripheral blood cell counts remained normal. We speculate that the diffuse but focally inhomogeneous uptake of ${ }^{18}$ F-FDG may inferentially represent the residual activity of normal hematopoiesis. This may also explain why there are more reported cases of ALL initially detected by PET/CT than AML. It is likely that AML causes peripheral blood cytopenia earlier than ALL, so the majority of cases are diagnosed by routine peripheral blood and bone marrow examinations. In contrast, ALL sometimes behaves like lymphoma and presents with a fever and high LDH level. These differences may explain to some extent the difference in the frequency of detecting acute leukemia by PET/CT between AML and ALL.

In conclusion, PET/CT is now being increasingly incorporated as part of routine health checkups in Japan. Therefore, we are likely to encounter a diffuse bone marrow uptake of ${ }^{18}$ F-FDG in this setting. Based on our experience, we strongly recommend that the blood counts and differentials should be closely followed for patients with a diffuse uptake of ${ }^{18} \mathrm{~F}-\mathrm{FDG}$ in the bone marrow but no abnormalities on a physical examination or blood tests.

If any changes in symptoms, physical examination findings, or blood tests are observed during follow-up, it is strongly recommended to perform a bone marrow examination without delay.

The authors state that they have no Conflict of Interest (COI).

\section{References}

1. Ennishi D, Maeda Y, Niiya M, Shinagawa K, Tanimoto M. Incidental detection of acute lymphoblastic leukemia on [18F] fluorodeoxyglucose positron emission tomography. J Clin Oncol 27: e269-e270, 2009.

2. Arslan F, Yilmaz M, Cakir T, Mert A. Significant contribution of fluorodeoxyglucose positron emission tomography/computed tomography (FDG PET/CT) in a case of acute Lymphoblastic leukemia presenting with fever on unknown origin. Intern Med 53: 789791, 2014.

3. $\mathrm{Su}$ K, Nakamoto Y, Nakatani K, Kurihara K, Hayakawa N, Togashi K. Diffuse homogenous bone marrow uptake of FDG in patients with acute lymphoblastic leukemia. Clin Nucl Med 38: e33-e34, 2013.

4. Stolzel F, Rolling C, Radke J, et al. 18F-FDG PET/CT for detection of extramedullary acute myeloid leukemia. Hematologica 96: 1552-1556, 2011.

5. Schollaert P, Loosen C, Andre' M, Chatelain B, Krug B. An atypical relapse of acute myeloid leukemia diagnosed 18F-by F-FDG PET/CT. Clin Nucl Med 37: 1018-1021, 2012.

6. Arimoto MK, Nakamoto Yuji, Koya Nakanishi, et al. Increased bone marrow uptake of $18 \mathrm{~F}-\mathrm{FDG}$ in leukemia patients: preliminary findings. Springer Plus 4: 521, 2015.

7. Inoue K, Goto R, Okada K, Kinomura S, Fukuda H. A bone marrow F-18 FDG uptake exceeding the liver uptake may indicate bone marrow hypersensitivity. Ann Nucl Med 23: 643-649, 2009.

8. Zhou M, Chen Y, Liu J, Huang G. A predicting model of bone marrow malignant infiltration in 18FDG PET/CT images with increased diffuse bone marrow FDG uptake. Journal of Cancer 9: 1737-1744, 2018.

The Internal Medicine is an Open Access journal distributed under the Creative Commons Attribution-NonCommercial-NoDerivatives 4.0 International License. To view the details of this license, please visit (https://creativecommons.org/licenses/ by-nc-nd/4.0/).

\section{(C) The Japanese Society of Internal Medicine Intern Med Advance Publication}

